\title{
Sostenibilidad de
}

\section{la deuda pública en los países norteños de América Latina}

\author{
Igor Paunovic
}

1

análisis de los indicadores de la deuda pública de ocho países norteños de América Latina muestra que los más vulnerables son Nicaragua y Honduras. Vulnerabilidad moderada exhiben Panamá, la República Dominicana, Costa Rica y El Salvador. Finalmente, en México y Guatemala el nivel de endeudamiento no es peligroso. Del posterior examen de cuatro indicadores de sostenibilidad fiscal, solamente México sale bien parado en todos los casos. Costa Rica y Guatemala presentan algunos problemas menores, mientras que algunas circunstancias especiales explican los buenos resultados de Nicaragua y la República Dominicana. El Salvador, Honduras, y Panamá no pueden sostener por mucho tiempo la política fiscal vigente en 2004. Finalmente, el análisis de la sensibilidad de la deuda ante un "frenazo súbito" de la entrada de capital externo advierte que conviene adoptar una actitud cautelosa respecto a la evolución futura de la deuda pública frente al aumento de las tasas de interés internacionales.

Oficial de Asuntos Económicos, 


\section{I}

\section{Introducción}

Gracias a las esperanzas que suscitaron las reformas macroeconómicas y estructurales y el regreso a la senda de crecimiento, el tema de la sostenibilidad fiscal de la deuda pública no figuró en forma prominente en la agenda de los gobiernos de los ocho países norteños de América Latina durante la mayor parte del decenio de 1990 y los primeros años de la década actual. Sin embargo, esto podría cambiar debido al lento crecimiento económico del período 2000-2003, así como al aumento de las tasas de interés internacionales desde mediados del 2004. Cabe preguntarse cuán vulnerables, en términos macroeconómicos, son estos países (Costa Rica, El Salvador, Guatemala, Honduras, México, Nicaragua, Panamá y la República Dominicana).

El tema de la sostenibilidad de la deuda pública cobró otra vez importancia recientemente en el mundo entero, debido a una serie de reestructuraciones o cesaciones de pagos de la deuda en países tan variados como Argentina, Ecuador, Pakistán, Rusia, Ucrania y Uruguay. Frente a eso, el Fondo Monetario Internacional comenzó a desarrollar mecanismos para una resolución ordenada de futuras crisis de la deuda. Esos mecanismos, no obstante, servirán en situaciones posteriores a las crisis. Una tarea aun más importante sería la de hacer hincapié en la prevención de las crisis de endeudamiento. Para poner de relieve que al respecto se observan algunas tendencias preocupantes en los países en desarrollo, el Fondo dedicó a este tema un capítulo de su World Economic Outlook, 2003 (FMI, 2003).

Por su parte, la CEPAL dedicó un capítulo de su Estudio económico de América Latina y el Caribe, 20032004 (CEPAL, 2004) al tema de la sostenibilidad de la deuda pública en la región. Allí destaca que en los últimos quince años la curva del comportamiento de dicha deuda toma la forma de U. De 1990 a 1996 la deuda medida en porcentajes del PIB se fue reduciendo, para repuntar a partir de 1997. Esto último coincidió con lo que la CEPAL llamó la "media década perdida". ${ }^{1}$

$\square$ El autor agradece los valiosos comentarios de José Octavio Martínez, Jorge Máttar, René Hernández y de un juez anónimo que comentó este artículo.

${ }^{1}$ De hecho, la deuda pública como porcentaje del PIB en 2004 era más alta que la deuda externa como porcentaje del PIB en 1982, cuando estalló la crisis de la deuda. Carrera Troyano (2004) analiza este punto más detalladamente.
El hecho de que la deuda exhiba hoy niveles mayores que hace siete años no es en sí preocupante. Sin embargo, la economía mundial se encuentra en la fase expansiva del ciclo económico, después de tres años de crecimiento muy bajo. Lo que habitualmente acompaña a esta fase del ciclo es la reactivación de la inflación y la reacción concomitante de las autoridades monetarias. La política monetaria se vuelve más restrictiva, lo que se refleja en una subida generalizada de las tasas de interés. Un signo claro de esta secuencia es el alza de las tasas de interés de la Reserva Federal estadounidense, que ha estado elevando su tasa de referencia desde mediados del 2004.

Por lo tanto, el período de tasas de interés muy bajas acabó, y lo que hay que preguntarse ahora es hasta qué nivel van a subir y cuáles serían las consecuencias en los países norteños de América Latina. Si las tasas suben a un nivel moderado y de forma paulatina, es probable que la deuda no se convierta en un problema, pero si llegan a niveles altos y de manera brusca, la sostenibilidad de la deuda puede convertirse en un tema central de la política económica.

En este contexto internacional, nos proponemos examinar el siguiente conjunto de preguntas: ¿Es posible que los países norteños de América Latina sufran una crisis de la deuda en los próximos dos o tres años? ¿Son sostenibles las trayectorias en que se hallan las finanzas públicas de estos países? Si no lo son, ¿qué magnitud tendría el ajuste fiscal necesario para volverlas sostenibles? Dadas las circunstancias nacionales e internacionales, ¿cuáles son las perspectivas de esos países en materia de deuda pública? Y, por último, ¿cuáles son los países más vulnerables en este momento?

En la sección II del artículo examinaremos la situación de estos ocho países en materia de deuda pública y presentaremos algunos indicadores clave de endeudamiento. Los indicadores (coeficientes tanto de acervo como de flujos) serán comparados con los umbrales internacionales que sugiere la literatura especializada. Estos indicadores, que representan medidas de endeudamiento ex post, sirven como una primera aproximación al tema.

En la sección III analizaremos los indicadores de sostenibilidad de la deuda pública en los países norteños de América Latina. De los numerosos indicadores de sostenibilidad fiscal propuestos en estudios teóricos, 
escogimos cuatro: el indicador de Blanchard (1990), el déficit macroajustado de Talvi y Végh (2000), el algoritmo recursivo de Croce y Juan-Ramón (2003) y el indicador de Calvo, Izquierdo y Talvi (2003) que analiza el descalce de las monedas. Dado que el análisis de la sostenibilidad de la deuda pública es al mismo tiempo el análisis de la sostenibilidad de la política fiscal, podremos también dilucidar la magnitud del ajuste fiscal requerido para colocar las finanzas en la trayectoria sostenible.

En la sección IV pondremos los resultados de las dos secciones anteriores en el contexto más amplio de la situación macroeconómica presente y futura de los países norteños de América Latina y su entorno inter- nacional. Se calculará la sensibilidad de la deuda en el caso hipotético de un "frenazo súbito" de la entrada de capital externo, que se manifiesta con una depreciación brusca, aumento de las tasas de interés, desaceleración del crecimiento y conversión de los pasivos contingentes en deuda pública. Esto indicará el orden de magnitud de los ajustes fiscales necesarios frente a lo que constituye el peor de los casos, pues en él se dan simultáneamente los cuatro efectos adversos señalados. Finalmente, analizaremos el comportamiento de algunas importantes fuentes de divisas, como las remesas, el turismo y la industria maquiladora.

En la sección V se presentan algunas conclusiones y recomendaciones de política.

\section{II}

\section{Indicadores de la deuda pública en los países norteños de América Latina}

Los indicadores de deuda pública nos dan una primera información acerca de su sostenibilidad. Son indicadores ex post, es decir, presentan los hechos en contraste con los indicadores de sostenibilidad, que nos proporcionan ex ante la magnitud del ajuste fiscal permanente necesario para que la deuda se vuelva sostenible. Los indicadores de deuda son los coeficientes de acervo y de flujo y nos facilitan la comparación internacional. De hecho, el Banco Mundial, el FMI y otras instituciones financieras suelen definir los valores críticos de algunos indicadores con fines de alerta y prevención.

La deuda pública externa representa un alto porcentaje de la deuda externa total en los países analizados. Como se desprende del cuadro 1, en todos ellos la deuda pública externa constituye más de la mitad de la deuda externa total. El porcentaje más bajo se encuentra en México (54\%), y el más alto en Nicaragua $(86 \%)$. Por eso, lo que pasa con la deuda pública determina la tendencia de la deuda externa, y viceversa. ${ }^{2}$

Otro elemento importante es la proporción de la deuda de corto plazo en la deuda externa total. Habitualmente se considera que si este indicador es inferior a $10 \%$ no debe alarmar a las autoridades económicas. Sin embargo, en cuatro de los ocho países la

\footnotetext{
${ }^{2}$ En la literatura económica se ha tratado de llegar a un marco teórico que mostraría explícitamente el vínculo entre la deuda pública y la deuda externa, pero hasta el momento los resultados han sido parciales. Véase, por ejemplo, Horne (1991), Parker y Kastner (1993) y Chalk y Hemming (2000).
}

Países norteños de América Latina: Deuda pública externa y deuda externa de corto plazo como proporción de la deuda externa total, 2002 (En porcentajes)

\begin{tabular}{lcccccccc}
\hline Indicador/País & Costa Rica & El Salvador & Guatemala & Honduras & México & Nicaragua & Panamá & R. Dominicana \\
\hline $\begin{array}{l}\text { Deuda pública externa/ } \\
\text { deuda externa total }\end{array}$ & 64,9 & 80,9 & 77,9 & 78,1 & 54,0 & 86,0 & 77,2 & 64,5 \\
$\begin{array}{l}\text { Deuda de corto plazo/ } \\
\text { deuda externa total }\end{array}$ & 31,0 & 17,0 & 19,9 & 9,7 & 7,0 & 8,5 & 4,5 & 32,3 \\
\hline
\end{tabular}

Fuente: Banco Mundial (2005). 
deuda de corto plazo sobrepasa ese $10 \%$ y en otros tres se aproxima a él, lo que apunta a la existencia de una dinámica que en circunstancias adversas podría ser peligrosa. Entonces, teniendo en cuenta la coyuntura internacional actual y futura, es preciso analizar las tendencias de la deuda pública y hacer seguimiento continuo de este tema.

Muchos de los análisis de la deuda utilizan el valor presente neto de ella en vez de su valor nominal, alegando que es un dato más preciso porque refleja qué proporción de la deuda es concesional. También se suele usar la deuda neta en vez de la bruta, descontando los activos líquidos de los gobiernos, con la misma argumentación. Esto sería correcto si tuviéramos los datos de los pasivos no registrados que son deuda implícita de los gobiernos. En esta categoría se encuentran los pasivos extrapresupuestarios, los pasivos contingentes, los pasivos provenientes del sistema de seguridad social, y otros. ${ }^{3}$ Su efecto es aumentar la razón deuda/PIB, pero la falta de datos sobre los pasivos no registrados en los países que analizamos nos impide conocer su magnitud. Por este motivo, consideramos que la deuda bruta nominal como proporción del PIB es un indicador menos sujeto a error que la deuda neta o el valor presente neto de la deuda. ${ }^{4}$ La incertidumbre respecto a las cifras proviene de los problemas metodológicos de registros contables en varios países de los ocho analizados. Las prácticas de doble contabilidad, de dejar fuera de registro algunas operaciones fiscales o de emplear una contabilidad fiscal muy heterodoxa (como en $\mathrm{Pa}$ namá hasta hace poco), distorsionan las cifras oficiales y no reflejan de manera fidedigna la realidad fiscal del sector público. En fin, dado que los problemas de subregistro son probablemente importantes pero de magnitud desconocida, lo mejor que podemos hacer es señalar esta situación y usar la deuda bruta nominal en vez de la neta, o el valor presente neto de la deuda.

Uno de los indicadores más usados es la deuda pública total (interna más externa) del sector público no financiero (SPNF) como porcentaje del PIB. Sin embargo, no hay consenso acerca de qué nivel de deuda es "peligroso". De hecho, los valores críticos varían

\footnotetext{
${ }^{3}$ Más detalles sobre esto proporcionan CEPAL (1998) y FMI (2002).

${ }^{4}$ Una de las características más perversas de los pasivos contingentes es la asimetría de ocurrencia. Durante las épocas buenas permanecen como contingentes en la mayoría de los casos, pero en las épocas malas dejan de ser contingentes y se convierten en deuda pública en una alta proporción. En una crisis catastrófica como la de la deuda externa del decenio de 1980 incluso las deudas privadas se convierten en deuda pública, especialmente las del sector financiero.
}

considerablemente de acuerdo con el tipo de economía a la que se aplica. Un valor considerado aceptable para los países industrializados se considera demasiado peligroso para los países en desarrollo. Por ejemplo, uno de los criterios del Tratado de Maastricht para la adopción de la moneda común en la Unión Europea fue el de tener la deuda pública por debajo de $60 \%$ del PIB. En cambio, el FMI (2003) opina que el nivel sostenible de la deuda pública en las economías emergentes es de sólo $25 \%$ del PIB.

Este nivel muy bajo, aunque controversial, es consecuencia de los cambios ocurridos en la economía mundial en los últimos 35 años. En un mundo cada vez más globalizado, con el capital financiero atravesando sin dificultades las fronteras de los países, la estabilidad macroeconómica y financiera internacional es un bien público global. Sin embargo, la provisión mundial de este bien público en la actualidad es muy deficiente. ${ }^{5}$ En consecuencia, la arquitectura financiera internacional existente obliga a los países asumir de manera individual el costo de la estabilidad macroeconómica, tarea que en su momento fue demasiado onerosa incluso para países asiáticos como la República de Corea, cuyo manejo macroeconómico es ejemplar.

Sea como sea, estamos en un mundo donde la sostenibilidad de la deuda pública se ve como un problema exclusivo de los países individuales. Por lo tanto, es casi inevitable aceptar que el valor crítico de esa sostenibilidad sea solamente $25 \%$ del PIB. Otro valor crítico que recomienda el Fondo (FMI, 2002) es el de 40\% del PIB. Debajo de esta proporción la probabilidad de que ocurra una crisis de la deuda es inferior a 5\%. Sin embargo, la probabilidad de crisis aumenta a un rango de $15 \%$ a $20 \%$ cuando se sobrepasa el nivel de deuda equivalente a $40 \%$ del PIB. En otras palabras, la relación entre la probabilidad de crisis de deuda y el nivel de la deuda no es lineal. ${ }^{6}$ Por eso es todavía más importante examinar el nivel de la deuda y su sostenibilidad.

¿Cómo están situados los países norteños de América Latina respecto a esto? En el gráfico 1 presentamos los valores de la deuda del sector público no financiero $^{7}$ como proporción del PIB para los ocho países

\footnotetext{
${ }^{5}$ Véase, por ejemplo, CEPAL (2002).

${ }^{6}$ Pattillo, Poirson y Ricci (2002) también observan una relación no lineal entre la deuda externa y el crecimiento económico. Específicamente, encuentran que el impacto de la deuda externa en el crecimiento se convierte en negativo a partir de un nivel de deuda de 35\%-40\% del PIB y/o de un nivel de deuda de 160\%-170\% del valor de las exportaciones.

${ }^{7}$ Salvo en los casos de Guatemala y la República Dominicana, que informan solamente de las cifras del gobierno central.
} 
estudiados. Tres países tienen un nivel más alto que el promedio de América Latina y el Caribe. Dos de ellos, Nicaragua y Honduras, son los países que entraron en la Iniciativa para la reducción de la deuda de los países pobres muy endeudados (Iniciativa PPME). Panamá también tiene un nivel de endeudamiento bastante alto. Los niveles de deuda en torno a $48 \%$ del PIB en Costa Rica y la República Dominicana, y de $42 \%$ en El Salvador, ubican a estos países por arriba del valor crítico de $40 \%$, pero por debajo del criterio del Tratado de Maastricht. México es el único país cuya deuda parece presentar probabilidades de crisis muy bajas, y Guatemala es el único país que cumple con el muy estricto requisito de sostenibilidad de tener una deuda pública inferior al 25\% del PIB.
Además de la proporción del PIB, otro indicador clave es la deuda pública total como proporción de los ingresos públicos (gráfico 2). Un mismo nivel de deuda pública como proporción del PIB puede arrojar muy diferentes resultados como proporción de los ingresos públicos. Costa Rica y la República Dominicana ilustran bien esta situación con una razón deuda/PIB en torno a $48 \%$ y un indicador deuda/ingresos públicos de $136 \%$ y $294 \%$ en 2004, respectivamente. Esto es reflejo de diferentes tamaños del Estado en los dos países, y sirve para matizar el indicador deuda/PIB, puesto que indica la carga sobre la capacidad del fisco de captar ingresos.

Otro indicador importante mide la relación entre la deuda pública externa y las exportaciones de bienes

GRÁFICO 1

Países norteños de América Latina: Deuda del sector público no financiero como porcentaje del PIB

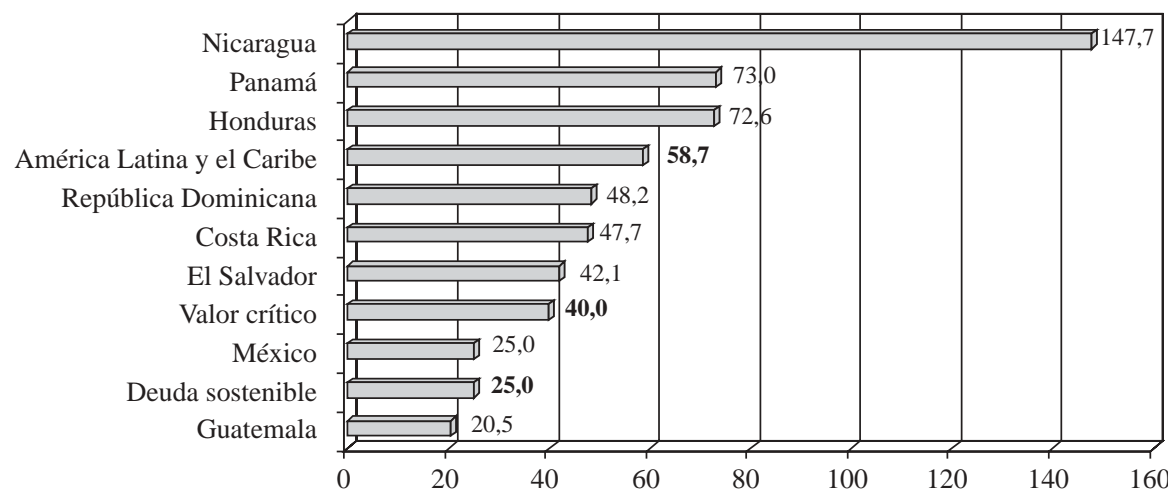

Fuente: Cálculos propios, sobre la base de cifras oficiales.

GRÁFICO 2

Países norteños de América Latina: Deuda pública como porcentaje de los ingresos públicos, 2004

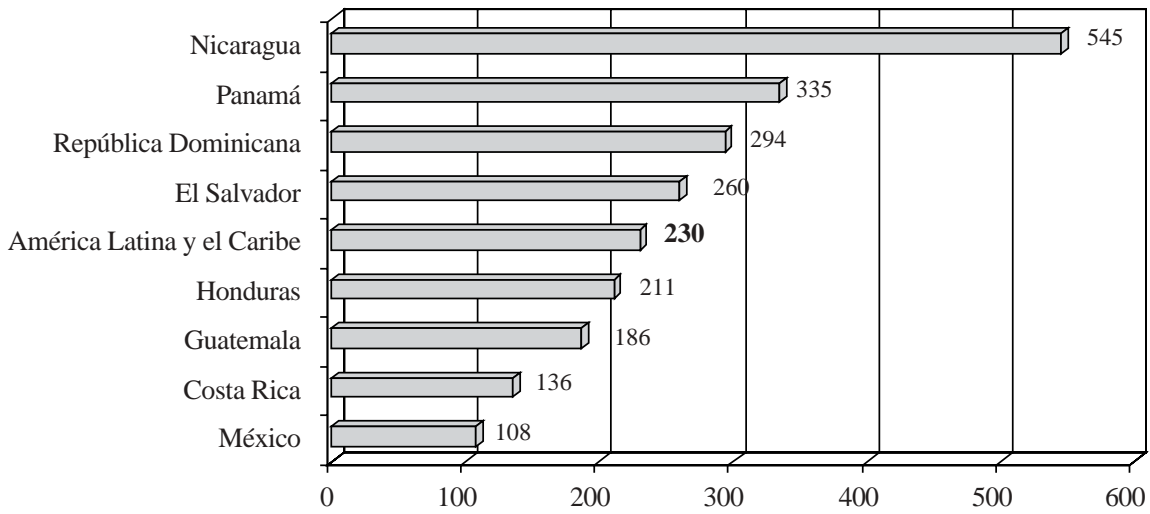

Fuente: Cálculos propios, sobre la base de cifras oficiales. 
GRÁFICO 3

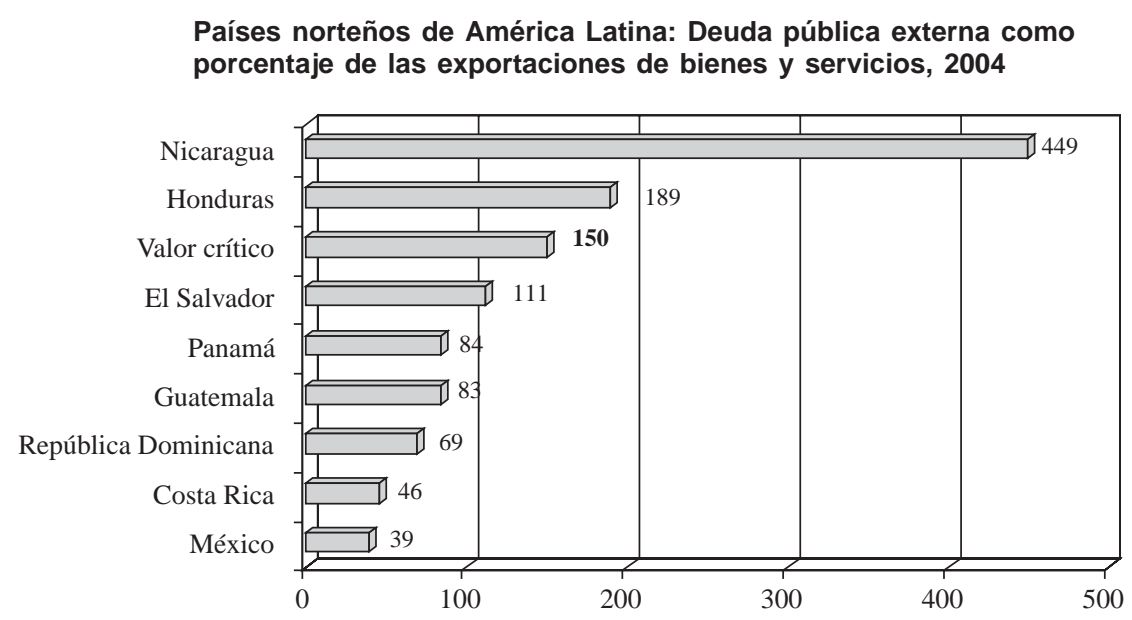

Fuente: Cálculos propios, sobre la base de cifras oficiales.

GRÁFICO 4

\section{Países norteños de América Latina: Razón entre la amortización de la deuda y nuevos desembolsos, 2004}

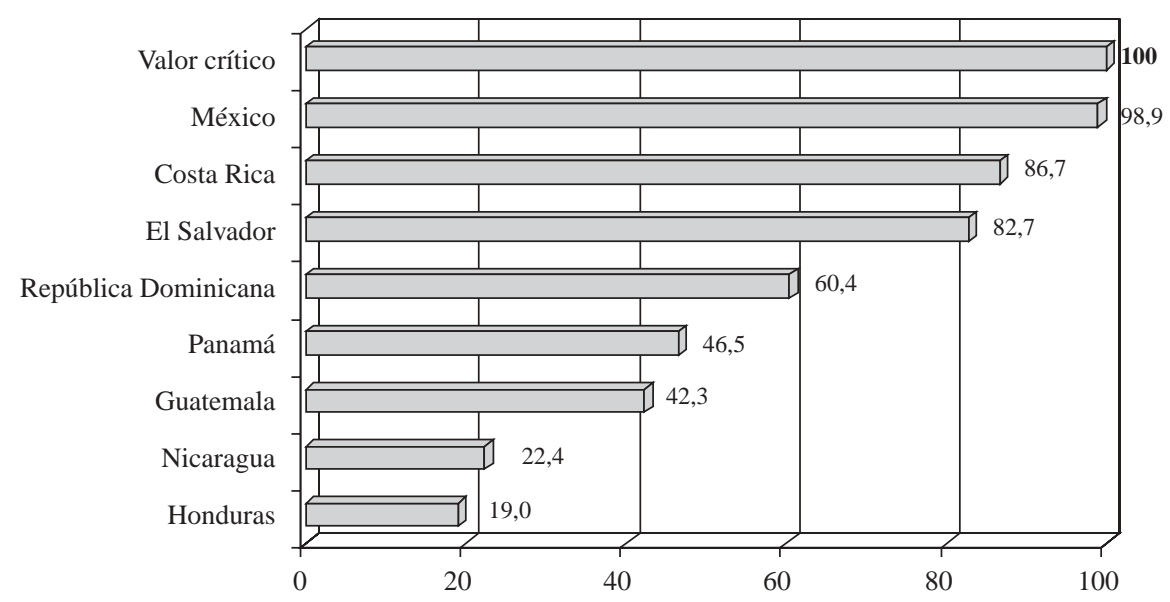

Fuente: Cálculos propios, sobre la base de cifras oficiales.

y servicios (gráfico 3). El valor crítico de $150 \%$ se usó para determinar los países que entrarían en la Iniciativa PPME, pero se midió a través del valor presente neto de la deuda pública externa. Esto nos proporciona el indicador de la carga sobre las exportaciones, o sea, sobre la capacidad de generar divisas. En este caso, la República Dominicana, por ejemplo, aparece entre los países con más capacidad de generación de divisas, en contraste con lo que hemos podido concluir de los primeros dos indicadores. México es el país en mejor posición, mientras que Nicaragua y Honduras se hallan en el otro extremo.
También es preciso calcular la razón entre la amortización de la deuda y los nuevos desembolsos (gráfico 4). Si este indicador —razón rotatoria (revolving ratio) - es superior a 100, la deuda no se refinancia con una nueva deuda. En contraste, si el indicador es inferior a 100, la deuda se refinancia con una deuda nueva, prolongando la dinámica existente de endeudamiento. Lamentablemente, ningún país norteño de América Latina se ubica en el lado "bueno" de este indicador (mayor de 100). México es el país mejor posicionado, puesto que casi llega al valor crítico, con Costa Rica y El Salvador relativamente cerca. Otros 
GRÁFICO 5

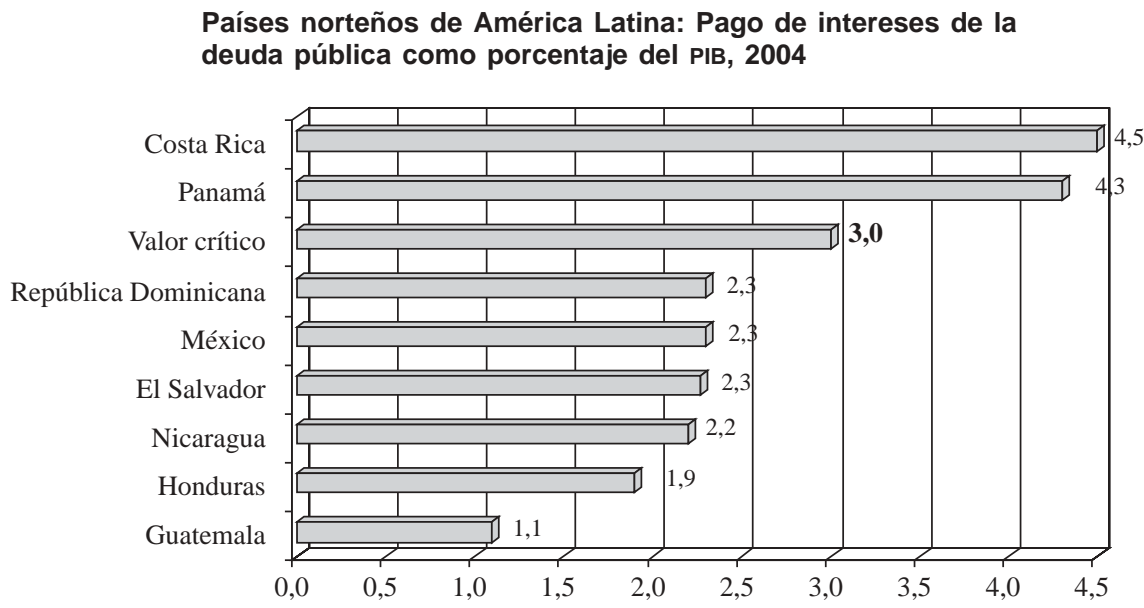

Fuente: Cálculos propios, sobre la base de cifras oficiales.

CUADRO 2

Países norteños de América Latina: Indicadores de la deuda pública, 2004

\begin{tabular}{|c|c|c|c|c|c|c|c|c|}
\hline & Costa Rica & El Salvador & Guatemala & Honduras & México & Nicaragua & Panamá & R. Dominicana \\
\hline Deuda externa/PIB & 21,1 & 30,2 & 14,3 & 68,3 & 11,5 & 118,3 & 52,6 & 33,9 \\
\hline Deuda interna/PIB & 26,6 & 11,9 & 6,2 & 4,3 & 13,4 & 29,4 & 20,4 & 14,3 \\
\hline Deuda pública total/PIB & 47,7 & 42,1 & 20,5 & 72,6 & 25,0 & 147,7 & 73,0 & 48,2 \\
\hline Deuda pública total/ingresos públicos & 135,9 & 283,2 & 186,2 & 210,9 & 107,7 & 54,0 & 334,7 & 293,9 \\
\hline Deuda externa/exportaciones & 45,5 & 111,1 & 83,4 & 189,0 & 38,5 & 449,3 & 83,8 & 68,7 \\
\hline Reservas internacionales netas/deuda externa & 51,6 & 39,5 & 89,4 & 33,0 & 78,8 & 8,0 & $\ldots$ & 9,4 \\
\hline Intereses externos/exportaciones & 2,8 & 7,0 & 4,1 & 2,5 & 4,7 & 9,4 & 5,7 & 3,8 \\
\hline Amortización/desembolsos (deuda externa) & 86,7 & 82,7 & 42,3 & 19,0 & 98,9 & 22,4 & 46,5 & 60,4 \\
\hline Intereses externos/PIB & 1,3 & 1,9 & 0,6 & 1,2 & 1,0 & 0,6 & 3,6 & 1,9 \\
\hline Intereses internos/PIB & 3,2 & 0,4 & 0,5 & 0,7 & 1,3 & 1,6 & 0,7 & 0,4 \\
\hline Intereses totales/PIB & 4,5 & 2,3 & 1,1 & 1,9 & 2,3 & 2,2 & 4,3 & 2,3 \\
\hline Deuda pública total per cápita (en dólares) & 2065 & 985 & 436 & 719 & 1594 & 1227 & 3016 & 997 \\
\hline
\end{tabular}

Fuente: Cálculos propios, sobre la base de cifras oficiales.

países están muy por debajo, lo que apunta a una tendencia potencialmente peligrosa en el futuro si no hay cambios radicales.

El pago de intereses de la deuda pública como porcentaje del PIB nos muestra qué tan onerosos son para el país esos intereses (gráfico 5). El valor crítico que se menciona en la literatura especializada se ubica en 3\% del PIB. De acuerdo con eso, Costa Rica y Panamá son los países donde este indicador es superior al valor crítico. También es importante destacar que estos dos países son los que tienen el mayor porcentaje de deuda interna en la deuda pública total. ${ }^{8}$ En

\footnotetext{
${ }^{8}$ Con excepción de Nicaragua.
}

consecuencia, se puede inferir que las tasas de interés que ellos pagan sobre la deuda interna son bastante elevadas.

El cuadro 2 muestra los indicadores analizados y algunos otros que pueden ser de interés, como las reservas internacionales netas de los bancos centrales como proporción de la deuda externa pública, el servicio de la deuda externa pública como proporción de las exportaciones de bienes y servicios, y otros. Todos estos indicadores entregan información valiosa sobre la magnitud del endeudamiento público y sirven para formarse una opinión acerca de los riesgos posibles en el futuro próximo.

Según los indicadores de endeudamiento, estos ocho países muestran una enorme diversidad. Los países 
con indicadores más problemáticos son Nicaragua y Honduras. Como ambos ya están incluidos en la Iniciativa PPME, las reglas del juego para ellos son diferentes. Además, estos dos países tienen programas de ajuste con el FMI y un componente importante de ellos está dedicado al ajuste fiscal. En el segundo grupo entran Panamá, la República Dominicana, Costa Rica y El Salva- dor, cuyos indicadores muestran una vulnerabilidad mayor pero no extrema, como en los países del primer grupo. Esto se puede convertir en un problema si las condiciones actuales, que son favorables, empeoran significativamente. Por último, México y Guatemala forman un grupo aparte, pues sus indicadores no señalan un nivel de endeudamiento peligroso.

\section{III}

\section{Indicadores de sostenibilidad fiscal}

\section{Algunas consideraciones teóricas acerca de estos indicadores}

En la teoría económica se ha advertido que los resultados de la política fiscal actual satisfacen la condición de solvencia cuando los superávit primarios futuros son iguales a la deuda pública en términos del valor presente neto de ambas variables. ${ }^{9}$ En otras palabras, el gobierno es solvente intertemporalmente, ya que puede continuar con las políticas actuales. Sin embargo, esta condición no se presta de manera fácil para llegar a un indicador operacional. Conocer los futuros superávit primarios es imposible. Además, como lo advierte Horne (1991), la solvencia del gobierno es una condición necesaria pero no suficiente para que la política fiscal actual sea sostenible. Se requiere también conocer el comportamiento futuro del sector privado, ya que esto determina las futuras tasas de interés y el crecimiento económico.

Para evitar estos problemas, en la literatura especializada se ha propuesto utilizar indicadores más sencillos que tienen requisitos de información mucho menores que los basados en el concepto de solvencia intertemporal. ${ }^{10}$ Sin embargo, tales indicadores no tienen una base teórica clara para su construcción. Uno de sus problemas más graves es la arbitrariedad. En general, miden el esfuerzo necesario para que la razón deuda/PIB se mantenga en el nivel actual. Este nivel,

\footnotetext{
${ }^{9}$ Por ejemplo, Horne (1991), Talvi y Végh (2000).

${ }^{10}$ Existe otra línea de investigación sobre la sostenibilidad que utiliza métodos econométricos. Sin embargo, no hay consenso sobre cómo se debería analizar el problema de la sostenibilidad (Chalk y Hemming, 2000). Además, es preciso contar con muchos datos para tener grados de libertad suficientes, lo que para muchos países en desarrollo es una exigencia prohibitiva. Por estas dos razones no exploramos aquí esa línea de investigación.
}

no obstante, podría ser demasiado alto o demasiado bajo, y estos indicadores no proporcionan criterio alguno para determinarlo. Por eso es necesario considerarlos junto con los indicadores de endeudamiento que se presentaron en la sección II.

\section{Cuatro indicadores de sostenibilidad fiscal en los países norteños de América Latina}

Presentamos aquí cuatro indicadores de sostenibilidad. Cada uno destaca algún elemento relevante para el análisis de sostenibilidad. El primero es el indicador de brecha primaria de corto plazo (Blanchard, 1990) que nos proporciona el nivel del saldo primario ${ }^{11}$ permanente necesario para estabilizar la deuda en proporción al PIB en su nivel actual:

$$
s p^{*}-s p=\left(r_{t}-n_{t}\right) b-s p
$$

donde $s p *$ es el saldo primario permanente necesario para estabilizar la deuda, $s p$ es el saldo primario existente, $r_{t}$ es la tasa de interés real tendencial, $n_{t}$ es la tasa de crecimiento tendencial del PIB y $b$ es la razón deuda/PIB. Si el saldo primario permanente es superior al saldo primario actual, la brecha primaria es positiva. Eso significa que la política fiscal no es sostenible, ya que tiende a aumentar el nivel de la deuda en relación al PIB. En el caso contrario, donde el saldo primario permanente es inferior al saldo primario actual, la política fiscal tiende a disminuir el nivel de la deuda con respecto al PIB.

El cuadro 3 proporciona los datos del saldo primario existente en 2004, el saldo primario requerido

\footnotetext{
${ }^{11}$ Saldo primario es la diferencia entre los ingresos totales y los gastos totales sin el pago de intereses.
} 
(En porcentajes y porcentajes del PIB)

\begin{tabular}{|c|c|c|c|c|c|c|c|c|}
\hline Indicador/País & Costa Rica & El Salvador & Guatemala & Honduras & México & Nicaragua & Panamá & R. Dominicana \\
\hline Saldo primario existente en 2004 & 0,5 & $-0,2$ & 0,2 & 0,1 & 2,5 & 2,0 & $-0,7$ & 3,9 \\
\hline Tasa de interés implícita tendencial & 4,9 & 5,4 & 5,1 & 13,2 & 1,6 & 1,4 & 6,6 & 3,0 \\
\hline Tasa de interés implícita en 2004 & 2,8 & 4,7 & 1,3 & 8,8 & 1,1 & $-4,6$ & 4,9 & $-4,4$ \\
\hline Crecimiento tendencial & 4,6 & 3,6 & 3,7 & 3,0 & 3,0 & 4,2 & 3,9 & 4,8 \\
\hline Crecimiento real en 2004 & 4,2 & 1,5 & 2,7 & 5,0 & 4,4 & 5,1 & 6,2 & 2,0 \\
\hline Saldo primario tendencial & 0,1 & 0,7 & 0,3 & 7,4 & $-0,4$ & $-4,1$ & 1,9 & $-0,9$ \\
\hline Brecha primaria tendencial & $-0,4$ & 0,9 & 0,0 & 7,3 & $-2,8$ & $-6,0$ & 2,6 & $-4,8$ \\
\hline Brecha primaria requerida en 2004 & $-1,2$ & 1,5 & $-0,5$ & 2,6 & $-3,3$ & $-16,3$ & $-0,2$ & $-7,0$ \\
\hline
\end{tabular}

Fuente: Cálculos propios sobre la base de cifras oficiales.

en 2004, el saldo primario tendencial, la brecha primaria tendencial y la brecha primaria requerida en 2004. El saldo primario tendencial y la brecha primaria tendencial son indicadores que fueron propuestos por Blanchard con la tasa de crecimiento tendencial de los últimos diez años ${ }^{12}$ y la tasa de interés real de los últimos diez años. Nosotros usamos la tasa de interés "implícita", que se calcula como el pago de intereses de la deuda como porcentaje del saldo de la deuda del período anterior, siguiendo lo sugerido en CEPAL (2004). Específicamente, la tasa de interés real se calculó como promedio ponderado de las tasas de interés sobre la deuda interna y la deuda externa

$$
r_{t}=r_{t}^{D} \frac{b_{t-1}^{D}}{b_{t-1}}+r_{t}^{E} \frac{b_{t-1}^{E}}{b_{t-1}}
$$

donde $r_{t}^{D}$ es la tasa de interés sobre la deuda interna, $b_{t-1}^{D}$ es la razón deuda interna/PIB en el período anterior, $b_{t-1}$ es la razón deuda pública total/PIB en el período anterior, $r_{t}^{E}$ es la tasa de interés sobre la deuda pública externa, y $b_{t-1}^{E}$ es la razón deuda pública externa/PIB en el período anterior. ${ }^{13}$

También hicimos una pequeña modificación al indicador de Blanchard, calculando la brecha primaria con los datos de crecimiento económico y la tasa de interés real en el año 2004. Este indicador lo denomi-

\footnotetext{
${ }^{12}$ La tasa de crecimiento tendencial fue estimada de la manera habitual, usando el filtro Hodrick-Prescott con el $\alpha=100$.

${ }^{13}$ La tasa de interés real interna se calculó usando la variación del índice de precios al consumidor. Para obtener la tasa de interés real externa, siguiendo lo sugerido en CEPAL (1988), se usó la variación del valor unitario de las exportaciones de bienes.
}

namos el saldo primario requerido en 2004. Mientras que el indicador tradicional de Blanchard refleja el saldo primario con los datos "normalizados" durante por lo menos un ciclo económico, nuestra modificación capta las condiciones coyunturales del año para el que se calcula este indicador. Esto puede ser útil tanto para apoyar su calidad de indicador idóneo que capta las condiciones específicas o temporales como para compararlo con las condiciones más "normales" que refleja el indicador del saldo primario tendencial.

En la interpretación de los resultados hay que tener presente las características especiales de la coyuntura actual. Las tasas de interés se encuentran en un nivel muy bajo, al tiempo que el crecimiento del PIB es relativamente alto. Por eso, la brecha primaria tendencial es mejor indicador que la brecha primaria requerida en 2004. Para mayor claridad, en el cuadro 3 también presentamos los datos de la tasa de interés implícita real tendencial, la tasa de interés implícita en 2004, el crecimiento tendencial y el crecimiento real en 2004. Como se puede observar, la tasa de interés real implícita tendencial es en todos los casos superior a la tasa de interés real implícita en 2004. En contraste, el crecimiento tendencial es superior al crecimiento real en 2004 solamente en cuatro países. En otros cuatro países el crecimiento tendencial es inferior al crecimiento real registrado en 2004. Finalmente, la tasa de interés real implícita en 2004 es inferior a la tasa de crecimiento real en 2004 en seis de los ocho países. Por estas razones, el saldo primario requerido en 2004 es inferior al saldo primario existente en la mayoría de los casos.

Según los resultados, la política fiscal en Costa Rica tiende a estabilizar el nivel de endeudamiento público en 2004, ya que el saldo primario actual es 
mayor que el saldo primario tendencial y el requerido. Sin embargo, es preocupante que el país gaste anualmente más de $4 \%$ del PIB en pago de intereses. El Salvador, Honduras y Panamá en 2004 tienen brechas primarias y requeridas positivas, y por lo tanto, si siguen la misma política fiscal, la deuda pública como porcentaje del PIB aumentará. ${ }^{14}$ En contraste, los resultados de Guatemala y México muestran que la política fiscal actual es sostenible.

Los casos de Nicaragua y la República Dominicana son un tanto especiales. El saldo primario requerido en 2004 para Nicaragua está muy sesgado por la tasa de interés real que resulta negativa por los diminutos pagos de interés, producto de atrasos del pago de la deuda del país y de las condonaciones del pago en virtud de la Iniciativa PPME. Otro factor importante es la tasa de crecimiento relativamente alta $(5,1 \%)$, lo que se refleja en el saldo primario requerido negativo. Ambos factores también aparecen en el caso del saldo primario tendencial. En cambio, el saldo primario positivo de la República Dominicana en 2004 resulta de la cobertura insuficiente de los datos fiscales que presenta el país. Como se informa solamente el resultado del gobierno central, no se incluye el déficit cuasi fiscal del banco central. Como este déficit estuvo en torno a 4\% del PIB en el 2004, con una cobertura más amplia los resultados de la política fiscal resultarían menos halagadores. De todos modos, el país hizo muchos esfuerzos para devolverle la credibilidad a la política macroeconómica después de la crisis bancaria de mayo del 2003. Además, el saldo primario requerido en el 2004 es negativo porque la tasa de interés real que pagó el país fue negativa en cuanto a la deuda interna. La tasa de inflación, que era $60 \%$ anual a comienzo del 2004 y que había ido atenuándose desde entonces, fue la causa de la tasa de interés real negativa en 2004. Finalmente, con los valores de parámetros más habituales (el crecimiento muy alto en el decenio de 1990), la República Dominicana no debería tener problemas con la sostenibilidad de la deuda: según los datos del superávit primario tendencial, puede darse el lujo de tener saldos primarios negativos de hasta 4,8\% del PIB y al mismo tiempo mantener el nivel de la deuda como proporción del PIB.

\footnotetext{
14 Panamá escapa parcialmente de esta conclusión con la brecha primaria requerida negativa en 2004. Hay que tener presente, sin embargo, que la tasa de crecimiento en 2004 fue de 6,2\%, más alta que la tasa de interés implícita $(4,9 \%)$. La incógnita es por cuánto tiempo se podría prolongar esta situación, dado el proceso de aumento de las tasas de interés.
}

Según este indicador, en suma, la política fiscal es sostenible en Costa Rica, México y Guatemala. ${ }^{15}$ Los casos de Nicaragua y la República Dominicana son especiales y deben interpretarse con cuidado, tomando en cuenta sus circunstancias especiales. El resto de los países necesita hacer un esfuerzo para volver a la senda de sostenibilidad fiscal según el indicador de Blanchard.

El segundo indicador de sostenibilidad fiscal que exploramos es el del déficit primario macroajustado, propuesto por Talvi y Végh (2000). La motivación de este indicador es la gran volatilidad de las variables macroeconómicas en América Latina, que hace que el déficit en un momento dado pueda diferir grandemente del que se daría en condiciones macroeconómicas normales. Para solucionar esta situación, los autores proponen calcular un déficit primario macroajustado, que es el que existiría si la economía siguiera su trayectoria de largo plazo (PIB en su nivel potencial, ingresos fiscales no afectados por situaciones coyunturales, etc.).

La idea básica tras este indicador es contrastar el déficit macroajustado con el valor que resulta de considerar los intereses que se están devengando efectivamente en un momento dado, junto con el nivel de la deuda y la tasa de crecimiento del país que imperan en ese momento. El indicador se define como:

$$
I_{t}^{M} \equiv \frac{(r-g)}{(1+g)} b_{t-1}+d_{t}^{M}
$$

donde $r$ es la tasa de interés real para el año de análisis, $g$ es el crecimiento real en el año de análisis, y $d_{t}^{M}$ es el déficit primario macroajustado, es decir, aquel que existiría bajo las condiciones macroeconómicas normales. ${ }^{16} \mathrm{La}$ dificultad de este indicador es determinar cuáles exactamente son las condiciones "normales" para una economía. Los autores mencionados sugieren identificar dichas condiciones mediante un análisis minucioso realizado por expertos. Nosotros empleamos un procedimiento relativamente sencillo para las ocho economías analizadas: como variable sustitutiva de las condiciones normales, usamos para cada país los

\footnotetext{
15 Es preciso matizar estas conclusiones con lo que se notó anteriormente sobre la calidad de los datos. Si los datos utilizados no recogen de manera fidedigna toda la realidad fiscal de los países, los indicadores de sostenibilidad tienden a perder su utilidad. Lamentablemente, no hay manera de averiguar la magnitud de la discrepancia entre las cifras oficiales y la realidad fiscal.

16 Sólo para el desarrollo de este indicador, definimos el déficit como la diferencia entre gastos e ingresos, de modo tal que cuando es negativo, se trata de superávit.
} 
indicadores de la brecha de PIB tendencial con miras a determinar los años en los cuales la brecha entre el PIB real y el PIB tendencial fue mínima. Tomamos el saldo primario de ese año y lo incluimos como el saldo primario macroajustado en el cuadro 4. Además, incluimos información de intereses pagados como porcentaje del PIB, para fines de ilustración.

Tal como se desprende de la ecuación (3), la sostenibilidad de la política fiscal requiere que este indicador tome un valor igual o menor que cero. Si es mayor que cero, la deuda será insostenible en el tiempo.

Se advierte que el indicador del ajuste necesario en el 2004 es negativo en todos los países examinados, salvo en Honduras. Por lo tanto, solamente en Honduras la política fiscal no fue sostenible en el 2004. Las condiciones excepcionales que causaron estos resultados (tasas de interés bajas y crecimiento relativamente alto) se explicaron anteriormente con los resultados del indicador de Blanchard. Puede verse que la carga de servicio de la deuda, incluso en tiempos de tasas de interés bajas, es significativa. Sin embargo, por los esfuerzos fiscales que han hecho los países, la mayoría de ellos está en situación de sostenibilidad bajo las condiciones actuales.

El tercer indicador de sostenibilidad fiscal, que corresponde a una propuesta de Croce y Juan-Ramón (2003), se basa en un algoritmo recursivo derivado de la ley de movimiento de la razón deuda/PIB, dada la función de reacción de las autoridades fiscales. Sencillamente, dichas autoridades determinan un cierto nivel de la deuda pública en relación al PIB y se calcula el superávit primario necesario para alcanzarlo. Este indicador se calcula de la siguiente manera:

$$
I_{s f}=\frac{1+r_{t}}{1+n_{t}}-\frac{s p-s p^{o}}{b_{t-1}-b^{o}}
$$

donde $I_{s f}$ es el indicador de sostenibilidad fiscal, $s p^{o}$ es el saldo primario que prevalecerá una vez que se alcance la meta en cuanto a razón deuda/PIB, y $b^{o}$ es el nivel de la razón deuda/PIB que las autoridades quieren alcanzar. Por supuesto, nosotros no sabemos qué nivel quisieran alcanzar las autoridades fiscales de los ocho países analizados. Por eso decidimos tomar para todos los países, como meta uniforme, la de bajar la razón deuda/PIB diez puntos porcentuales. Esto es obviamente demasiado restrictivo en el caso de Guatemala y demasiado laxo en el caso de Nicaragua, además de ser totalmente arbitrario. Sin embargo, este ejercicio nos da una idea de cómo funciona el indicador de sostenibilidad fiscal (cuadro 5).

Lo importante de este indicador es que su módulo sea menor a 1. Si esta condición se cumple, el país estaría en posición de llegar a reducir su coeficiente de deuda pública/PIB al nivel que se propone, reducción

CUADRO 4

Países norteños de América Latina: El déficit primario

macroajustado y el ajuste necesario, 2004

(En porcentajes y porcentajes del PIB)

\begin{tabular}{lcccccccc}
\hline Indicador/País & Costa Rica & El Salvador & Guatemala & Honduras & México & Nicaragua & Panamá & R. Dominicana \\
\hline Intereses pagados/PIB & 4,5 & 2,3 & 1,1 & 1,9 & 2,3 & 2,2 & 4,3 & 2,3 \\
Déficit primario macroajustado & $-4,5$ & $-3,1$ & $-0,3$ & 0,0 & $-3,5$ & $-2,3$ & $-3,4$ & 0,0 \\
Valor del indicador en 2004 & $-5,12$ & $-1,75$ & $-0,58$ & 2,66 & $-4,32$ & $-20,19$ & $-4,18$ & $-3,38$ \\
\hline
\end{tabular}

Fuente: Cálculos propios sobre la base de cifras oficiales.

CUADRO 5

Países norteños de América Latina: Indicador de sostenibilidad fiscal, 2004

(En porcentajes del PIB)

\begin{tabular}{|c|c|c|c|c|c|c|c|c|}
\hline Indicador/País & Costa Rica & El Salvador & Guatemala & Honduras & México & Nicaragua & Panamá & R. Dominicana \\
\hline Deuda total/PIB objetivo & 37,7 & 33,0 & 10,3 & 62,6 & 15,0 & 138,0 & 63,0 & 38,1 \\
\hline Saldo primario/PIB objetivo & 0,1 & 0,6 & 0,1 & 6,2 & $-0,2$ & $-3,7$ & 1,6 & $-0,7$ \\
\hline Indicador de sostenibilidad fiscal & 0,96 & 1,09 & 1,00 & 1,62 & 0,74 & 0,87 & 1,52 & 0,68 \\
\hline
\end{tabular}

Fuente: Cálculos propios sobre la base de cifras oficiales. 
que en nuestro caso es de diez puntos porcentuales. En consecuencia, Costa Rica, México, Nicaragua y República Dominicana podrían alcanzar esta meta sin mayores cambios en su política fiscal, mientras los demás países no podrían hacerlo. Guatemala, con el indicador de uno, es un caso intermedio. Los proponentes de este indicador sugieren recalcularlo cada tres meses, una vez que el gobierno decida qué nivel de deuda pública quiere alcanzar, para poder ajustar la política fiscal. De esta manera se puede seguir la evolución de la sostenibilidad trimestralmente, teniendo en cuenta la meta en materia de deuda pública, y hacer ajustes de manera oportuna.

El cuarto y último indicador de sostenibilidad fiscal que presentamos en este trabajo es el indicador del descalce de monedas propuesto por Calvo, Izquierdo y Talvi (2003). Esos autores parten del hecho de que la volatilidad de las variables macroeconómicas en América Latina es muy alta, y que la volatilidad de los flujos de capital lo es aún más. Por estas razones, un elemento crucial para la sostenibilidad de la deuda es su composición (qué monedas y en qué proporción la componen) comparada con la composición de la producción nacional (transable y no transable). En el caso de Argentina, los autores mencionados señalan que este indicador es trascendental para entender la crisis de 1998-2002 que desembocó en la cesación del pago de la deuda.

El indicador del descalce compara la proporción de deuda externa sobre deuda interna con la proporción de la producción de bienes transables sobre la de no transables en la economía. En un extremo tenemos el resultado en el cual el calce es perfecto (el indicador es 1), ya que los transables participan en el PIB en la misma proporción en que la deuda externa participa en la deuda pública total. El otro extremo es el descalce perfecto con el indicador 0 . El indicador parte de la descomposición de la deuda en interna y externa, y del PIB en transable y no transable:

$$
b=\frac{B+e B^{*}}{Y+e Y^{*}}
$$

donde $B$ es la deuda en términos de no transables, $e$ es el tipo de cambio real, $B^{*}$ es la deuda en términos transables, $Y$ es el PIB de no transables e $Y^{*}$ es el PIB de transables. ${ }^{17}$ Poniendo en relación la razón deuda no

\footnotetext{
${ }^{17}$ Los proponentes de este indicador sugieren representar esta última variable por las exportaciones de bienes y servicios.
}

transable/deuda transable y el PIB de no transables con el PIB de transables, llegamos al indicador del descalce de monedas $\left(I_{d m}\right)$ que toma los valores entre 0 y 1 :

$$
I_{d m}=\frac{B}{B^{*}} / \frac{Y}{Y^{*}}
$$

Obviamente, para El Salvador y Panamá, países que usan el dólar como su moneda, este indicador no tiene sentido, ya que el sector público capta los ingresos en la misma moneda en la cual ha contraído la mayor parte de su deuda (cuadro 6). Para los otros países, en cambio, es muy importante. Costa Rica es el país mejor posicionado, gracias a una mayor proporción de deuda interna en la deuda pública total y a una apertura comercial mayor que la de los demás países. México es otro país donde este indicador se halla en un nivel aceptable. ${ }^{18}$ En cambio, Guatemala, Honduras, Nicaragua y la República Dominicana tienen un descalce de monedas marcado o incluso severo. Sin embargo, en el caso de Guatemala esto no representa un problema grande gracias al bajo nivel de la deuda pública como porcentaje del PIB.

\section{3. ¿Qué podemos concluir después de examinar diversos indicadores de sostenibilidad fiscal?}

De los ocho países norteños de América Latina, solamente México sale bien parado en todos los casos. ${ }^{19}$ En este país el saldo primario existente en el 2004 fue mayor que el requerido para mantener el mismo nivel de la razón deuda pública/PIB, el descalce de monedas es aceptable, y la política fiscal es sostenible según el indicador del déficit primario macroajustado. Otros países registran resultados menos alentadores.

Un segundo grupo de países incluye a Costa Rica y Guatemala. En el caso de Costa Rica el problema es el nivel de la deuda más que el flujo de deuda y el monto alto de los pagos de intereses. En Guatemala, en cambio, el único problema es el severo descalce de monedas.

Circunstancias especiales, entre las cuales sobresalen las tasas de interés negativas, explican los buenos resultados de Nicaragua y la República Dominicana. Este último país, con los parámetros registrados

\footnotetext{
${ }^{18}$ Martner y Tromben (2004) sugieren que el valor de este indicador cercano a 0,5 se puede considerar razonable.

${ }_{19}$ De nuevo, es preciso matizar estas conclusiones para todos los países, teniendo en cuenta lo que se señaló anteriormente acerca de los problemas de subregistro y otros.
} 
(En porcentajes y coeficientes)

\begin{tabular}{lcccrrrrr}
\hline Indicador/País & Costa Rica & El Salvador & Guatemala & Honduras & México & Nicaragua & Panamá & R. Dominicana \\
\hline B/eB & 2,90 & $\ldots$ & 0,60 & 0,15 & 1,14 & 0,42 & $\ldots$ \\
Y/eY* & 3,70 & $\ldots$ & 7,90 & 4,70 & 2,20 & 5,30 & $\ldots$ & 1,03 \\
Indicador del descalce de monedas & 0,78 & $\ldots$ & 0,08 & 0,03 & 0,51 & 0,08 & $\ldots$ & 4,00 \\
\hline
\end{tabular}

Fuente: Cálculos propios sobre la base de cifras oficiales.

en los últimos 15 años, puede sortear los problemas de sostenibilidad de la deuda pública sin mayores contratiempos. Queda por verse, sin embargo, si las altas tasas de crecimiento del PIB pueden repetirse en el futuro. Por lo tanto, es difícil evaluar correctamente tal sostenibilidad en estos dos países.

El Salvador, Honduras y Panamá no pueden sostener por mucho tiempo la política fiscal que estaba vigente en el 2004, ya que aumentaría la razón deuda pública/PIB. Además, Honduras y Nicaragua presentan un fuerte descalce de monedas, lo que podría ser otro factor agravante en una eventual crisis de la deuda. El hecho de que Honduras y Nicaragua estén incluidos en la Iniciativa PPME, sin embargo, matiza estas conclusiones, ya que para estos países se aplican otras reglas del juego respecto a la deuda.

Finalmente, cuatro países tienen que hacer un esfuerzo adicional si quieren reducir la razón deuda pública/PIB en diez puntos porcentuales. En fin, la situación respecto a la sostenibilidad de la deuda pública no es alarmante, pero hay luces amarillas que apuntan a la necesidad de un seguimiento permanente.

\section{IV}

\section{La sensibilidad de la deuda pública a los choques externos}

La volatilidad macroeconómica en América Latina significa que los indicadores de sostenibilidad fiscal pueden cambiar bruscamente en muy poco tiempo. La deuda pública en la República Dominicana, por ejemplo, se duplicó como porcentaje del PIB durante el año 2003 por la crisis bancaria y sus efectos en las variables macroeconómicas, como la recesión, la depreciación del tipo de cambio real, el aumento de la tasa de interés y el rescate del sistema bancario. Similares factores se pueden encontrar en las recientes crisis de Argentina (Calvo, Izquierdo y Talvi, 2003) y Uruguay (Rial y Vicente, 2004). Por esta razón es de suma importancia el análisis de la sensibilidad de la deuda pública a choques externos como los que sufrió, por ejemplo, Argentina: "frenazos súbitos" de los flujos de capital externo, en la terminología de Calvo, Izquierdo y Talvi (2003).

Estos autores denominaron frenazos súbitos a situaciones en las cuales se produce una detención ines- perada y prolongada de los flujos de capital. Después de la crisis rusa de agosto de 1998 hubo uno de estos episodios, que tuvo fuertes repercusiones, sobre todo en los países del Cono Sur. Uno de los efectos de estos episodios suele ser una depreciación grande del tipo de cambio real que aumenta la razón deuda pública externa/PIB y en consecuencia la razón deuda pública total/PIB, y dificulta el servicio de la deuda. Los choques adversos son especialmente intensos en los países con un importante descalce de las monedas entre la deuda y los ingresos, lo que puede conducir incluso a la cesación del pago de la deuda. El choque se propaga en la economía a través del aumento de las tasas de interés, y se traduce en un crecimiento económico bajo o incluso en una recesión. Al mismo tiempo, la situación fiscal empeora por el aumento del servicio de la deuda, la reducción de los ingresos fiscales y la conversión de los pasivos contingentes en deuda pública. Esta mezcla peligrosa 
puede tener consecuencias catastróficas, como sucedió en Argentina en el 2002.

En esta sección nos interesa examinar los efectos de un choque catastrófico del tipo frenazo súbito, pero no hay que confundir este análisis con los acontecimientos reales. El hecho de que las tasas de interés internacionales empezaran a subir no significa que preveamos un frenazo súbito en la región. Más bien, el alza de las tasas de interés es una señal de que el ambiente macroeconómico benigno está cambiando a uno menos benigno. Dentro de este nuevo ambiente puede haber otros factores positivos o negativos que no estarían relacionados con el frenazo súbito. Uno de ellos es el elevado precio del petróleo, que tiene efectos particularmente negativos en siete de los ocho países analizados. Otro, puede ser el aumento de los precios de las materias primas, lo que resultaría en un deterioro adicional de la relación de intercambio, o en un crecimiento más lento que el registrado en la década de 1990. Todo esto significa que el análisis que sigue es más bien hipotético. Sin embargo, nos proporciona el orden de magnitud de los ajustes fiscales necesarios en el peor de los casos, es decir, cuando los cuatro efectos adversos del frenazo súbito se producen de manera simultánea.

Para conocer los posibles efectos de los choques de este tipo en los países norteños de América Latina, hicimos cuatro simulaciones cuyos resultados se presentan abajo. Los efectos individuales de cada choque deben sumarse, ya que en un caso de frenazo súbito de los flujos de capital externo los cuatro efectos suelen darse a la vez. En la literatura especializada se emplean diferentes supuestos para calcular la sensibilidad de la deuda. Melhado (2003), por ejemplo, calcula los efectos en la deuda pública usando una depreciación real de $30 \%$, un menor crecimiento (la tasa de crecimiento del PIB histórica menos dos desviaciones estándares) y un alza de las tasas de interés (el promedio histórico más dos desviaciones estándares). Yamauchi (2004) usa supuestos en los que se reduce el crecimiento del PIB en dos puntos porcentuales y aumentan las tasas de interés en 200 puntos básicos. Calvo, Izquierdo y Talvi (2003) utilizan una depreciación real de $50 \%$, que es más acorde con la experiencia de los países del Cono Sur en los últimos siete años. También calculan cambios con la suposición de un aumento de las tasas de interés de 200 puntos básicos y de una reducción del crecimiento de un punto porcentual.

Nosotros quisimos ver qué tan sensible es la deuda pública a una depreciación del tipo de cambio real de $50 \%$. El segundo supuesto es una reducción de la tasa de crecimiento de dos desviaciones estándares respecto al crecimiento desde 1980 hasta la fecha. El tercer supuesto es un aumento de la tasa de interés implícita de 200 puntos básicos, situación no tan extrema, ya que para muchos países latinoamericanos esa fue la norma entre 1998 y 2002. Finalmente, el cuarto supuesto es un aumento de la deuda pública equivalente a diez puntos porcentuales del PIB por la conversión de pasivos contingentes en deuda pública. Calculamos todos estos efectos con los indicadores de Blanchard en su forma original (con la tasa de crecimiento tendencial y la tasa de interés real en los últimos diez años) y con el saldo primario requerido según datos reales del 2004, ambos ajustados por los supuestos adoptados.

El cuadro 7 muestra el impacto de una depreciación real de $50 \%$ en la deuda pública. Está claro que en el caso de El Salvador y Panamá no hay cambios, ya que son economías dolarizadas. Después calculamos el saldo primario requerido para mantener este nivel de deuda bajo las condiciones que regían en el 2004 y bajo las condiciones medias de los últimos diez años (el saldo primario tendencial requerido).

Los resultados repiten el patrón encontrado en la sección anterior. Costa Rica, Guatemala y México registraron saldos primarios en el 2004 que son suficientes para sortear los efectos de una depreciación real de $50 \%$. En el otro extremo están El Salvador, Honduras y Panamá, donde los saldos requeridos son mayores que los observados en el 2004. Por último, Nicaragua y la República Dominicana tienen resultados positivos, pero aquí también vale la advertencia que se hizo hacia el final de la sección III.

En el caso de frenazo súbito de los flujos de capital externo el efecto no sería solo un cambio de precios relativos en la forma de una depreciación grande. Habría también una desaceleración de crecimiento del PIB que podría ser hasta dramático, como sucedió en Argentina, donde el PIB se contrajo en torno a 11\% en el 2002. Nosotros usamos un supuesto menos drástico, en el cual el crecimiento experimenta una reducción de dos desviaciones estándares. ${ }^{20} \mathrm{Se}$ calcula el crecimiento usando como base tanto el del año 2004 como el crecimiento tendencial. Dado que la desaceleración del crecimiento del PIB se añade al efecto de la depreciación real, la magnitud del ajuste fiscal requerido aumenta con los cálculos que se presentan en el cuadro 8 .

Un efecto adicional que sufren los países en crisis es el aumento de las tasas de interés (cuadro 9).

${ }^{20}$ La desviación estándar se calculó para el período 1980-2003. 
CUADRO 7

Países norteños de América Latina: La sensibilidad de la deuda pública a una depreciación real de $50 \%$

(En porcentajes y porcentajes del PIB)

\begin{tabular}{|c|c|c|c|c|c|c|c|c|}
\hline Indicador/País & Costa Rica & El Salvador & Guatemala & Honduras & México & Nicaragua & Panamá & R. Dominicana \\
\hline $\begin{array}{l}\text { Deuda pública imputada con } \\
\text { depreciación de } 50 \%\end{array}$ & 59,5 & 43,0 & 27,5 & 106,8 & 30,8 & 207,3 & 73,0 & 65,1 \\
\hline Saldo primario observado en el 2004 & 0,5 & $-0,2$ & 0,2 & 0,1 & 2,5 & 2,0 & $-0,7$ & 3,9 \\
\hline Saldo primario requerido & $-1,3$ & 2,3 & $-0,6$ & 4,0 & $-3,5$ & $-22,1$ & $-0,2$ & $-8,1$ \\
\hline Saldo primario tendencial requerido & $-0,3$ & 0,9 & 0,2 & 10,7 & $-2,9$ & $-7,8$ & 2,7 & $-5,1$ \\
\hline
\end{tabular}

Fuente: Cálculos propios sobre la base de cifras oficiales.

CUADRO 8

Países norteños de América Latina: La sensibilidad de la deuda pública a una desaceleración de crecimiento de dos desviaciones estándares

(En porcentajes y porcentajes del PIB)

\begin{tabular}{|c|c|c|c|c|c|c|c|c|}
\hline Indicador/País & Costa Rica & El Salvador & Guatemala & Honduras & México & Nicaragua & Panamá & R. Dominicana \\
\hline $\begin{array}{l}\text { Crecimiento en el } 2004 \text { menos dos } \\
\text { desviaciones estándares }\end{array}$ & 2,4 & $-1,9$ & 0,0 & 4,4 & 2,8 & $-0,7$ & 3,8 & 0,0 \\
\hline Crecimiento tendencial menos & & & & & & & & \\
\hline dos desviaciones estándares & 2,8 & 0,3 & 1,0 & 2,4 & 1,4 & $-1,6$ & 1,5 & 2,9 \\
\hline Saldo primario requerido & $-0,3$ & 3,0 & 0,2 & 4,6 & $-3,0$ & $-10,2$ & 1,5 & $-6,8$ \\
\hline Saldo primario tendencial requerido & 0,7 & 2,4 & 0,9 & 11,4 & $-2,4$ & 4,2 & 4,4 & $-3,8$ \\
\hline
\end{tabular}

Fuente: Cálculos propios sobre la base de cifras oficiales.

CUADRO 9

Países norteños de América Latina: Sensibilidad de la deuda pública a un alza de las tasas de interés

(En porcentajes y porcentajes del PIB)

\begin{tabular}{lcccccccr}
\hline Indicador/País & Costa Rica & El Salvador & Guatemala & Honduras & México & Nicaragua & Panamá & R. Dominicana \\
\hline $\begin{array}{l}\text { Tasa de interés implícita en el 2004 } \\
\text { + 200 puntos base }\end{array}$ & 4,8 & 6,7 & 3,3 & 10,8 & 3,1 & $-2,6$ & 6,9 & $-2,4$ \\
Tasa de interés real (implícita) & 6,9 & 7,4 & 7,1 & 15,2 & 3,6 & 3,4 & 8,6 & 5,0 \\
+ 200 puntos base & 0,9 & 3,8 & 0,7 & 6,8 & $-2,4$ & $-6,0$ & 3,0 & $-5,5$ \\
Saldo primario requerido & 1,9 & 3,2 & 1,5 & 13,5 & $-1,8$ & 8,3 & 5,9 & $-2,5$ \\
Saldo primario tendencial requerido & 1,9 & & & & & & & \\
\hline
\end{tabular}

Fuente: Cálculos propios sobre la base de cifras oficiales.

Como anotan Calvo, Izquierdo y Talvi (2003), un aumento de 200 puntos básicos de las tasas de interés que perdura varios años no es un evento aislado. De hecho, los márgenes del índice de bonos de mercados emergentes (EMBI) ${ }^{21}$ en 2001 se mantuvieron más de 200 puntos básicos por encima del nivel anterior a la crisis rusa de 1998. Nosotros añadimos 200 puntos

${ }^{21} \mathrm{EMBI}=$ Emerging Markets Bond Index básicos a la tasa de interés implícita en el 2004 y a la tasa de interés implícita tendencial. Con esta modificación calculamos el saldo primario requerido y el saldo primario tendencial requerido, que, como es de esperar, siguen aumentando.

El último cálculo que hicimos fue añadir el efecto de los pasivos contingentes (cuadro 10). En una situación de crisis los pasivos contingentes se convierten en deuda pública en una alta proporción. Por eso usamos el supuesto del aumento de la deuda pública 
(En porcentajes del PIB)

\begin{tabular}{|c|c|c|c|c|c|c|c|c|}
\hline Indicador/País & Costa Rica & El Salvador & Guatemala & Honduras & México & Nicaragua & Panamá & R. Dominicana \\
\hline \multicolumn{9}{|l|}{ Deuda con pasivos contingentes } \\
\hline (+10\% del PIB) & 69,5 & 52,1 & 37,5 & 116,8 & 40,8 & 217,3 & 83,0 & 75,1 \\
\hline Saldo primario requerido & 1,2 & 4,7 & 1,1 & 7,4 & $-2,4$ & $-6,2$ & 3,3 & $-5,7$ \\
\hline Saldo primario tendencial requerido & 2,3 & 3,9 & 2,1 & 14,8 & $-1,6$ & 8,8 & 6,6 & $-2,3$ \\
\hline
\end{tabular}

Fuente: Cálculos propios sobre la base de cifras oficiales.

CUADRO 11

América Latina (ocho países norteños): La contribución al deterioro de las finanzas públicas de los cuatro efectos adversos causados por el frenazo súbito

(En porcentajes del PIB y porcentajes)

\begin{tabular}{|c|c|c|c|c|c|c|c|c|}
\hline Indicador/País & Costa Rica & El Salvador & Guatemala & Honduras & México & Nicaragua & Panamá & R. Dominicana \\
\hline $\begin{array}{l}\text { Superávit primario tendencial } \\
\text { requerido con frenazo súbito }\end{array}$ & 2,3 & 3,9 & 2,1 & 14,8 & $-1,6$ & 8,8 & 6,6 & $-2,3$ \\
\hline $\begin{array}{l}\text { Superávit primario tendencial } \\
\text { requerido sin frenazo súbito }\end{array}$ & $-0,4$ & 0,9 & 0,0 & 7,3 & $-2,8$ & $-6,0$ & 2,6 & $-4,8$ \\
\hline Diferencia causada por el frenazo súbito & 2,7 & 3,0 & 2,1 & 7,6 & 1,2 & 14,8 & 3,9 & 2,5 \\
\hline Contribución de la depreciación & 1,7 & 0,0 & 6,6 & 46,1 & $-11,7$ & $-11,7$ & 1,4 & $-12,4$ \\
\hline Contribución del menor crecimiento & 39,4 & 47,7 & 36,8 & 8,9 & 41,7 & 80,4 & 43,4 & 51,4 \\
\hline Contribución del alza de las tasas de interés & 43,9 & 28,3 & 26,7 & 28,2 & 51,7 & 27,9 & 37,1 & 52,5 \\
\hline Contribución de los pasivos contingentes & 15,0 & 24,0 & 29,9 & 16,9 & 18,2 & 3,3 & 18,0 & 8,5 \\
\hline Total de los cuatro efectos adversos & 100 & 100 & 100 & 100 & 100 & 100 & 100 & 100 \\
\hline
\end{tabular}

Fuente: Cálculos propios sobre la base de cifras oficiales.

de diez puntos porcentuales del PIB. El hecho de que los rescates bancarios sean muy costosos (en el caso de la República Dominicana en el 2003, por ejemplo, llegó al equivalente de $20 \%$ del PIB), significa que nuestro supuesto no es exagerado. Como antes, este efecto se suma a los efectos adversos anteriores.

Esta simultaneidad de los efectos adversos es crucial para entender cuán peligrosos son los frenazos súbitos de los flujos de capital externo. Frente al deterioro de todas las variables macroeconómicas al mismo tiempo, las autoridades tienen estrecho margen de maniobra. Por eso es importante tratar de evitar acontecimientos de esta índole, entre otras cosas, con una política prudente de endeudamiento. Para los países analizados, el ajuste total de las finanzas públicas (es decir, el saldo requerido para mantener el nivel de la razón deuda pública/PIB y además encarar los cuatro efectos de un posible frenazo súbito) varía entre uno negativo de 1,6\% del PIB en México hasta uno de 14,8\% del PIB en Honduras, tomando en cuenta el saldo primario tendencial. De nuevo, los datos de la República Domi- nicana, que no incluyen el enorme déficit cuasi fiscal del banco central, sesgan fuertemente el resultado. Cuando se incluye ese déficit, el saldo primario tendencial requerido se torna positivo (1,7\% del PIB). En definitiva, tomando en cuenta los cuatro efectos, sólo México está inequívocamente bien; la República Dominicana se salva por las circunstancias señaladas, y Nicaragua dejaría de salvarse por registrar un saldo observado menor que el saldo tendencial requerido.

¿Qué otras opciones tienen las autoridades económicas? La respuesta depende de las circunstancias individuales de cada país, pero nuestro ejercicio de análisis de la sensibilidad de la deuda puede darnos algunas pistas. En el cuadro 11 presentamos la importancia relativa de cada uno de los cuatro efectos adversos presentados arriba. Concretamente, de la cifra del saldo primario tendencial del cuadro 10 sustraemos el saldo primario tendencial en el 2004 sin frenazo súbito. Dado que la diferencia es producto de los cuatro efectos analizados, calculamos la contribución porcentual de cada uno. 
(En porcentajes)

\begin{tabular}{lcccccccc}
\hline Año / País & Costa Rica & El Salvador & Guatemala & Honduras & México & Nicaragua & Panamá & R. Dominicana \\
\hline 2005 & 3,0 & 2,5 & 3,0 & 4,5 & 3,6 & 4,0 & 4,5 & 3,5 \\
2006 & 3,0 & 2,5 & 3,0 & 4,0 & 3,5 & 4,0 & 4,0 & 4,0 \\
\hline
\end{tabular}

Fuente: CEPAL (2005).

Encontramos que los datos por países varían enormemente. ${ }^{22}$ Primero, hay que notar que la diferencia causada por el frenazo súbito es solamente de 1,2\% del PIB en el caso de México, mientras que en el caso de Nicaragua llega a casi $15 \%$ del PIB. En la mayoría de los casos, el frenazo súbito requeriría un ajuste fiscal de entre $2 \%$ y $7 \%$ del PIB. Por su peso relativo en el deterioro de la situación fiscal, sobresalen dos de los cuatro efectos adversos del frenazo súbito. El primer lugar lo ocupa el crecimiento menor, que es la variable más importante en todos los países analizados, salvo en Honduras. El segundo lugar corresponde al alza de las tasas de interés, lo que tiene extraordinaria importancia porque estamos en un período de aumento de las tasas de interés internacionales. Los otros dos efectos tienen significación menor.

¿Cómo se inserta este análisis de sensibilidad de la deuda pública en un contexto macroeconómico más amplio? Como hemos visto, el crecimiento económico es una de las variables más importantes para la sostenibilidad de la deuda pública. En este plano la situación de los ocho países no es de exuberancia, pero tampoco es crítica. Según las proyecciones del Estudio Económico de América Latina y el Caribe 20042005 (CEPAL, 2005), estas economías tendrán en promedio un crecimiento moderado en el bienio 20052006 (cuadro 12). Esto es, por debajo del promedio de América Latina y el Caribe, que disfruta de una bonanza económica después de seis años de crecimiento

\footnotetext{
${ }^{22}$ En el cuadro 11 hay tres líneas en las que hay signos negativos que se pueden considerar como aberraciones. Además, por el redondeo la cifra del efecto de depreciación es ligeramente positiva cuando debería ser igual a cero en el caso de Panamá.
}

lento. Además, dos de las ocho economías estudiadas (El Salvador y Guatemala) crecen de forma moderada, apenas suficiente para equiparar la tasa demográfica. Por otro lado, Honduras, Nicaragua y Panamá exhiben tasas de crecimiento más altas, lo que ayudaría a reducir los indicadores y mejorar la sostenibilidad de la deuda pública.

Otros factores importantes dentro del contexto en que examinamos la sostenibilidad de la deuda pública son las remesas familiares, el turismo y la maquila. Las transferencias corrientes siguen aumentando a un ritmo fuerte, básicamente por el comportamiento dinámico de las remesas familiares. Esta fuente de divisas aporta el equivalente a 10\%-20\% del PIB a todos los países analizados, salvo Costa Rica, México y Panamá. Esto significa que esas remesas serían una fuente de divisas posiblemente independiente, y quizás estable y cada vez mayor, incluso en el caso de un frenazo súbito de los flujos de capital externo.

También son sectores dinámicos el turismo y la industria maquiladora. Ambos sufrieron contratiempos entre 2001 y 2003, pero ahora se hallan en franca recuperación en varios países. Sin embargo, hay diferencias importantes entre ellos. Mientras que la industria maquiladora fue el motor del crecimiento en la década de 1990, en la década del 2000 ya no promete repetir ese papel. La competencia china y los altos costos de producción en algunos de los países analizados ya han reducido su viabilidad. El turismo, en contraste, se encuentra en pleno auge en casi todos estos países, y con especial vigor en Honduras y Nicaragua. Esto significa una mayor afluencia de divisas, tanto por las inversiones extranjeras directas como por la llegada de turistas. 


\section{$\mathrm{V}$}

\section{Conclusiones}

El contexto macroeconómico en el bienio 2005-2006 será relativamente benigno, pero con una clara tendencia al deterioro. El crecimiento económico es moderado e incluso alto en algunos países, lo que facilita el servicio de la deuda. El aumento de las tasas de interés internacionales es un elemento de riesgo, pero si se da en forma paulatina, como ha ocurrido hasta hoy, no debería constituir un obstáculo insuperable para la política económica. Por el lado positivo se encuentra la estable y creciente oferta de divisas proveniente de las remesas familiares, el turismo y la industria maquiladora. Esto alivia considerablemente el problema del descalce de monedas que enfrentan algunos de los países estudiados.
En vista de todo lo anterior, conviene adoptar una actitud cautelosa ante la evolución futura de la deuda pública. Varios países son vulnerables al respecto, incluso si se excluyen los dos países más endeudados, Honduras y Nicaragua. La política económica debería dar mayor prioridad en los próximos años al manejo de la deuda pública. Un seguimiento permanente ayudaría a descubrir tempranamente los problemas potenciales y permitiría tomar medidas correctivas. Además, convendría eliminar las prácticas de subregistro que ocultan las verdaderas dimensiones de la deuda pública y la realidad fiscal de las finanzas públicas. Por último, y quizás lo más importante, la política fiscal debería seguir apuntando a la consolidación de la situación fiscal a través de reformas que fortalezcan los ingresos públicos.

\section{Bibliografía}

Banco Mundial (2005): Global Development Finance 2005: Mobilizing Finance and Managing Vulnerability, Washington, D.C.

Blanchard, O.J. (1990): Suggestions for a New Set of Fiscal Indicators, OECD Working Paper, $\mathrm{N}^{\circ} 79$, París, Organización de Cooperación y Desarrollo Económicos, abril.

Calvo, G.A., A. Izquierdo y E. Talvi (2003): Sudden Stops, the Real Exchange Rate, and Fiscal Sustainability: Argentina's Lessons, NBER Working Paper, No 9828, Cambridge, Massachusetts, National Bureau of Economic Research.

Carrera Troyano, M. (2004): La deuda externa en América Latina, veinte años después: una nueva media 'década perdida', Investigación económica, vol. 63, № 247, México, D.F., Facultad de Economía, Universidad Nacional Autónoma de México (UNAM), enero-marzo.

Chalk, N. y R. Hemming (2000): Assessing Fiscal Sustainability in Theory and Practice, IMF Working Paper 00/81, Washington, D.C., Fondo Monetario Internacional.

CEPAL (Comisión Económica para América Latina y el Caribe) (1988): La evolución del problema de la deuda externa en América Latina y el Caribe, serie Estudios e informes de la CEPAL, No 72, LC/G.1487/Rev.2-P, Santiago de Chile. Publicación de las Naciones Unidas, $\mathrm{N}^{\mathrm{o}}$ de venta: 88.II.G.10.

(1998): El pacto fiscal: fortalezas, debilidades, desafíos, LC/G.1997/Rev.1-P, Santiago de Chile. Publicación de las Naciones Unidas, $\mathrm{N}^{\circ}$ de venta: S.98.II.G.5.

(2002): Globalización y desarrollo, LC/G.2157(SES.29/3), Santiago de Chile, abril.

(2004): Estudio económico de América Latina y el Caribe, 2003-2004, LC/G.2255-P, Santiago de Chile. Publicación de las Naciones Unidas, $\mathrm{N}^{\mathrm{o}}$ de venta: S.04.II.G.2.

(2005): Estudio económico de América Latina y el Caribe, 2004-2005, LC/G.2279-P, Santiago de Chile, agosto. Publicación de las Naciones Unidas, $\mathrm{N}^{\mathbf{0}}$ de venta: S.05.II.G.2.

Croce, E. y V.H. Juan-Ramón (2003): Assessing Fiscal Sustainability: A Cross-Country Comparison, IMF Working Paper 03/145, Washington, D.C., Fondo Monetario Internacional.
Horne, J. (1991): Indicators of Fiscal Sustainability, IMF Working Paper 91/5, Washington, D.C., Fondo Monetario Internacional. FMI (Fondo Monetario Internacional) (2002): Assessing Sustainability, Washington, D.C., Departamento de Elaboración y Examen de Políticas. Disponible en <http://www.imf.org/external/np/pdr/ sus/2002/eng/052802.htm>

(2003): World Economic Outlook, 2003: Public Debt in Emerging Markets, Washington, D.C.

Martner, R. y V. Tromben (2004): La sostenibilidad de la deuda pública, el efecto bola de nieve y el 'pecado original', serie Gestión pública, No 46, LC/L.2150-P, Santiago de Chile, Comisión Económica para América Latina y el Caribe (CEPAL). Publicación de las Naciones Unidas, $\mathrm{N}^{\circ}$ de venta: S.04.II.G.75.

Melhado, O. (2003): Fiscal Sustainability and Resource Mobilization in the Dominican Republic, IMF Working Paper 03/19, Washington, D.C., Fondo Monetario Internacional.

Parker, K. y S. Kastner (1993): A Framework for Assessing Fiscal Sustainability and External Viability, with and Application to India, IMF Working Paper 93/78, Washington, D.C., Fondo Monetario Internacional.

Pattillo, C., H. Poirson y L. Ricci (2002): External Debt and Growth, IMF Working Paper 02/69, Washington, D.C., Fondo Monetario Internacional.

Rial, I. y L. Vicente (2004): Sostenibilidad y vulnerabilidad de la deuda pública: la experiencia uruguaya, XVI Seminario Regional de Política Fiscal, Santiago de Chile, Comisión Económica para América Latina y el Caribe (CEPAL).

Talvi, E. y C. Végh (2000): La sostenibilidad de la política fiscal: un marco básico, en E. Talvi y C. Végh (comps.), ¿Cómo armar el rompecabezas fiscal?: nuevos indicadores de sostenibilidad, Washington, D.C., Banco Interamericano de Desarrollo.

Yamauchi, A. (2004): Fiscal Sustainability: The Case of Eritrea, IMF Working Paper 04/7, Washington, D.C., Fondo Monetario Internacional. 